\title{
Determinação da massa específica de silagens de milho por método indireto
}

\author{
Determining the specific mass of corn silage by an indirect method
}

\author{
Michele Simili da Silva ${ }^{\mathrm{I}}$ Clóves Cabreira Jobim ${ }^{\mathrm{II}}$ Cássio Antonio Tormena ${ }^{\mathrm{III}}$ Moyses Calixto Júnior ${ }^{\mathrm{I}}$ \\ Jose Luis Soriane Filho ${ }^{\mathrm{I}}$ Juliano Roman $^{\mathrm{I}}$
}

\section{- NOTA -}

\section{RESUMO}

Com o objetivo de desenvolver um método alternativo para estimar a massa específica $(M E)$ de silagens, foram realizados dois trabalhos com silagens de milho em silos tipo trincheira. Os valores obtidos de resistência ao penetrômetro foram correlacionados com os valores de $M E$ obtidos com o uso de amostragens por cilindro metálico e então estimada a ME da silagem por meio de regressão. Houve alta relação positiva da resistência à penetração do cone metálico e a ME estimada com a ME observada. Concluiu-se que o penetrômetro pode ser utilizado como método indireto na determinação da ME de silagens de milho.

Palavras-chave: compactação, densidade, painel do silo.

\begin{abstract}
An alternative method to estimate the specific mass (SM) of silage were evaluated in two studies with corn silages in trench silos. The values of penetrometer resistance were correlated with the SM values obtained with the use of sampling by a metal cylinder and the SM of the silage was estimated by means of regression. Since there was a high positive relationship of penetration resistance of the metallic cone and SM estimated with SM observed, the penetrometer can be used as indirect method for determining the SM of corn silage.
\end{abstract}

Key words: compression, density, silo panel.

Maior penetração de ar na silagem durante a utilização ocorre quando a compactação da massa ensilada é insuficiente para uma adequada massa específica (ME). A ME é um dos fatores determinantes da qualidade final da silagem. A densidade e o teor de matéria seca determinam a porosidade da silagem, a qual estabelece a taxa de aeração e, posteriormente, influencia o grau de deterioração na armazenagem e na desensilagem (JOBIM et al., 2007).

Devido à dificuldade de compactação durante a ensilagem, as zonas mais porosas estão localizadas nas camadas superficiais e laterais do silo. Quanto maior a porosidade da massa, mais facilmente o ar poderá penetrar no seu interior. Assim, a redução da porosidade é de fundamental importância para conter a deterioração aeróbia (BERNARDES et al., 2009). Dessa forma, a compactação se faz necessária para o estabelecimento de condições de anaerobiose no interior do silo, estabelecendo relação inversa com a quantidade de $\mathrm{O}_{2}$ no silo.

De acordo com JOBIM et al. (2007), a massa específica é definida como a razão entre a massa de uma quantidade da substância e o volume por ela ocupado. Várias metodologias vêm sendo testadas para avaliação da ME de silagens, em sua maioria constituída por pesagem da massa de forragem retirada de um volume conhecido do silo, sendo os valores expressos em $\mathrm{kg}$ de MS ou MV $\mathrm{m}^{-3}$. A aplicação de métodos indiretos na avaliação da $\mathrm{ME}$ tem sido

'Programa de Pós-graduação em Zootecnia, Universidade Estadual de Maringá (UEM), Campus Universitário, Maringá, PR, Brasil. IIDepartamento de Zootecnia, UEM, Campus Universitário, Av. Colombo, 5790, 87020-900, Maringá, PR, Brasil. E-mail: ccjobim@uem.br. Autor para correspondência.

"IIDepartamento de Agronomia, UEM, Campus Universitário, Maringá, PR, Brasil. 
estudada, visando a facilitar operacionalmente a tomada desses dados em condições de campo. O grupo de estudos em forragens conservadas da Universidade Estadual de Maringá, com o objetivo de desenvolver um método alternativo para estimar a massa específica da silagem, conduziu dois experimentos com silagens de milho, utilizando o penetrômetro como um método indireto para se estimar a massa específica da silagem.

Os experimentos foram conduzidos na Fazenda Experimental de Iguatemi, pertencente à Universidade Estadual de Maringá O primeiro estudo foi realizado em silo tipo trincheira, com dimensões de $70 \mathrm{~m}$ de base por $2,4 \mathrm{~m}$ de altura e $20 \mathrm{~m}$ de comprimento, equivalendo a uma superfície de $16,8 \mathrm{~m}^{2}$. Para confecção da silagem, utilizou-se o híbrido DKB 789, com plantio em outubro de 2006 e colheita em fevereiro de 2007. A colheita do milho foi feita com a ensiladeira modelo JF 90Z10, regulada para corte de 5 a $8 \mathrm{~mm}$ de tamanho de partícula. Em agosto de 2007, o silo foi aberto e manejado diariamente para alimentação do rebanho leiteiro. O painel do silo foi dividido em três estratos verticais, sendo: (estrato superior $=$ profundidade de 0 a $80 \mathrm{~cm}$, mediano $=$ profundidade de 80 a $160 \mathrm{~cm}$ e basal $=$ profundidade de $160 \mathrm{a} 240 \mathrm{~cm}$ ).

O segundo estudo foi realizado em quatro silos tipo trincheira, revestidos por concreto, com dimensões de $3,80 \mathrm{~m}$ de base por $1,10 \mathrm{~m}$ de altura $\left(4,18 \mathrm{~m}^{2}\right)$ e $13 \mathrm{~m}$ de comprimento, equivalendo a um volume de $54,34 \mathrm{~m}^{3}$. Para confecção da silagem, utilizou-se o híbrido DKB 789, com plantio em novembro de 2007 e colheita em fevereiro de 2008. A colheita do milho foi feita com a ensiladeira modelo JF92Z10, regulada para corte de 11 a $13 \mathrm{~mm}$ para tamanho de partícula. Em maio de 2008, os silos foram abertos e manejados diariamente para alimentação de bovinos de corte. As silagens foram divididas em: silagem 1) com altura de corte do milho de $20 \mathrm{~cm}$ e sem adição do inoculante; silagem 2) com altura de corte de $40 \mathrm{~cm}$ e sem a adição do inoculante; silagem 3) com uma altura de corte de $20 \mathrm{~cm}$ e com inoculante e; silagem 4) com altura de corte de $40 \mathrm{~cm}$ e com adição do inoculante. Diariamente, eram retiradas camadas de aproximadamente $15 \mathrm{~cm}$ de silagem de cada silo para alimentação de bovinos confinados.

$\mathrm{Na}$ avaliação da $\mathrm{ME}$, foram realizadas três repetições por estrato para cada uma das duas semanas de avaliação do experimento 1 e três repetições por estrato para cada uma das silagens do experimento 2. A ME foi determinada por duas metodologias, primeiro, segundo descrito por HOLMES \& MUCK (1999) e SCHMIDT (2006), em que um cilindro metálico com $5,6 \mathrm{~cm}$ de diâmetro e $50 \mathrm{~cm}$ de comprimento, com borda cortante serrilhada, foi introduzido na massa ensilada por meio de rotação. A ME da silagem coletada com uso do cilindro foi determinada para o material verde e para o material seco $\left(55^{\circ} \mathrm{C} / 72\right.$ horas). Uma segunda metodologia foi proposta para avaliação da ME por meio de método indireto com uso de um penetrômetro. O penetrômetro é um equipamento de fácil acesso, utilizado normalmente para se estimar a resistência do solo à penetração em estudos de compactação. Os mais comuns consistem de um anel dinamométrico, uma haste com $1 \mathrm{~m}$ de comprimento e um cone que possui diâmetros variáveis, menores que o diâmetro da haste.

Com uso do aparelho, mediu-se a resistência oferecida pela massa da silagem à penetração de um cone metálico, em pelo menos 24 pontos em cada estrato da silagem do experimento $1 \mathrm{e}$ em 12 pontos por estrato para cada silagem do experimento 2. Para isso, o cone metálico foi empurrado para dentro da massa ensilada, em posição horizontal ao painel do silo, com uma velocidade constante de aproximadamente $2 \mathrm{~cm} \mathrm{~s}^{-1}$ até a haste, tendo penetrado $0,9 \mathrm{~m}$ na silagem. Foi obtida a leitura da máxima resistência em kgf e posteriormente corrigida para superfície do cone, obtendo o valor em MPa. Em seguida, os valores de resistência ao penetrômetro foram correlacionados com os valores de ME obtidos com o uso do cilindro metálico por meio de regressão e então estimada a ME da silagem.

Os estratos mediano e basal do painel do silo do experimento 1 apresentaram os maiores $(\mathrm{P}<0,05)$ valores de ME, não diferindo entre si tanto para massa específica do material seco (MEms) quanto para a massa específica do material verde (MEmv). Já o estrato superior do painel do silo avaliado neste mesmo experimento apresentou os menores valores de ME $\left(411,06 \mathrm{~kg} \mathrm{~m}^{-3}\right)$ no material verde (Tabela 1). Também houve efeito significativo dos estratos $(\mathrm{P}<0,05)$ sobre a ME do material verde das silagens do segundo experimento. $\mathrm{O}$ estrato superior apresentou uma ME média de $210,18 \mathrm{~kg} \mathrm{~m}^{-3}$, a menor entre os estratos. Estes dados corroboraram os obtidos por NEUMANN et al. (2007), que encontraram baixa ME e altas temperaturas no estrato superior em relação ao estrato inferior das silagens de milho avaliadas. A maior ME nos estratos inferiores do silo se deve ao efeito da maior compactação exercida pelo peso da massa da forragem.

Como se supunha, o estrato superior foi também o estrato que ofereceu a menor resistência à penetração do cone metálico com valores de $0,82 \mathrm{MPa}$ para a silagem avaliada no experimento 1 e $0,20 \mathrm{MPa}$ nas silagens avaliadas no experimento 2 , com ME verde de $411,06 \mathrm{~kg} \mathrm{~m}^{-3}$ e ME estimada do material verde de $218,90 \mathrm{~kg} \mathrm{~m}^{-3}$, respectivamente. Também VISSERS et al. (2007), utilizando o penetrômetro para inferir sobre a compactação da silagem, encontrou diferença significativa entre as camadas da silagem, obtendo na 
Tabela 1 - Massa específica calculada com base na matéria seca (MEms) e na matéria verde (MEmv) e resistência da massa ensilada à penetração do cone metálico (PCM) em diferentes estratos do painel do silo.

\begin{tabular}{lccc}
\hline Estratos & MEms $\left(\mathrm{kg} \mathrm{m}^{-3}\right)$ & MEmv $\left(\mathrm{kg} \mathrm{m}^{-3}\right)$ & PCM $(\mathrm{MPa})$ \\
\hline Superficial & $129,17 \mathrm{~b}$ & $411,06 \mathrm{~b}$ & $0,82 \mathrm{~b}$ \\
Mediana & $200,35 \mathrm{a}$ & $622,40 \mathrm{a}$ & $1,23 \mathrm{a}$ \\
Basal & $179,14 \mathrm{a}$ & $569,69 \mathrm{a}$ & $1,22 \mathrm{a}$ \\
Média & 169,55 & 534,38 & 1,09 \\
\hline
\end{tabular}

Médias na mesma coluna, seguidas de diferentes letras, diferem entre si pelo teste Tukey a 5\% de probabilidade.

camada superficial os menores valores de resistência à penetração com uma média de $0,25 \mathrm{MPa}$,comparada com 0,96MPa de resistência oferecida no estrato médio da silagem.

Houve relação linear e positiva entre a ME da silagem e a resistência à penetração do cone metálico nos dois estudos (Figura 1). No entanto, no segundo estudo, a equação linear ajustada teve um coeficiente de determinação baixo, explicando apenas $33 \%$ das variações observadas. Este baixo coeficiente pode ser atribuído às conformações superficiais dos silos utilizados neste segundo experimento, por proporcionarem uma menor compactação do material ensilado, alterando a correlação física de massa volume que pode ter influenciado a relação ME/ Resistência à penetração do cone metálico. Sendo assim, utilizou-se, neste experimento, a massa específica estimada do material verde (MEEmv) e do material seco (MEEms) das silagens em função da resistência $\left(\mathrm{x}_{1}\right)$ oferecida pela massa ensilada à penetração do cone metálico (MPa) e da posiçao $\left(\mathrm{x}_{2}\right)$ ocupada no silo, em que $\mathrm{x}_{2}=1$ para o estrato superior, $\mathrm{x}_{2}=2$ para o estrato mediano e $\mathrm{x}_{2}=3$ para o estrato basal. Para isso, empregaram-se as equações de regressão $\mathrm{y}=94,5358+137,968 \mathrm{x}_{1}+121,364 \mathrm{x}_{2}$ para o material verde, em que o modelo linear descreveu melhor a variação dos dados e $\mathrm{y}=36,9859+155,215 \mathrm{x}_{1}+217,425\left(\mathrm{x}_{1}\right)^{2}+30,8919 \mathrm{x}_{2}$ para o material seco, em que o modelo que melhor descreveu a variação dos dados foi o quadrático.

A relação obtida entre a ME estimada pelas equações acima com a ME observada para silagem, expressa em material verde e em material seco, foi linear e positiva. O coeficiente de determinação explicou $74 \%$ das variações para o material verde e $67 \%$ para o material seco.

A correlação obtida entre a massa específica observada para o material verde (MEmv) e a MEEmv de 0,86 indica uma alta associação positiva entre essas variáveis. O grau de associação entre a ME observada e a ME estimada para o material seco (MEEms) também foi alto e positivo $(0,82)$. Isso indica que essas variáveis estão diretamente e altamente relacionadas, sendo possível utilizar os valores estimados de ME pela equação de regressão para se determinar a ME de silagens de milho.

O penetrômetro pode ser utilizado como método indireto na determinação da massa específica de silagens de milho. Isso se dá devido à alta relação positiva que houve entre a resistência à penetração do cone metálico e $\mathrm{kg}$ de silagem $\mathrm{m}^{-3}$, em um primeiro estudo, e entre a massa específica estimada e a massa específica observada, em um segundo estudo.

Figura 1 - Relação entre massa específica da silagem $\left(\mathrm{kg} \mathrm{m}^{-3}\right)$ e a resistência à penetração do cone metálico (MPa) nos experimentos
1 e 2 respectivamente.

Ciência Rural, v.41, n.9, set, 2011. 


\section{REFERÊNCIAS}

BERNARDES, T. et al. Sealing strategies to control the top losses in horizontal silos. In: ZOPOLLATO, M. et al. INTERNATIONAL SYMPOSIUM ON FORAGE QUALITY AND CONSERVATION, 2004, Piracicaba. Proceedings... Piracicaba: FEALQ, 2009. p.209-224.

HOLMES, B.J.; MUCK, R.E. Factors affecting bunker silos densities. Madison: University of Wisconsin, 1999. 7p.

JOBIM, C.C. et al. Avanços metodológicos na avaliação da qualidade da forragem conservada. Revista Brasileira de Zootecnia, v.36, p.101-119, 2007. Disponível em: <http:// www.scielo.br/pdf/rbz/v36s0/13.pdf>. Acesso em: 31 mar. 2011. doi: $10.1590 / \mathrm{S} 1516-35982007001000013$.

NEUMANN, M. et .al. Efeito do tamanho de partícula e da altura de colheita das plantas de milho (Zea mays L.) sobre as perdas durante o processo fermentativo e o período de utilização das silagens. Revista Brasileira de Zootecnia, v.36, n.5, p.1603-1613, 2007. Disponível em: <http://www.scielo.br/pdf/ rbz/v36n5/24.pdf >. Acesso em: 31 mar. 2011. doi: 10.1590/ S1516-35982007000600024.

SCHMIDT, P. Perdas fermentativas na ensilagem, parâmetros digestivos e desempenho de bovinos de corte alimentados com rações contendo silagens de cana-de açúcar. 2006. 228f. Tese (Doutorado em Agronomia) Universidade de São Paulo, Escola Superior de Agricultura Luiz de Queiroz, Piracicaba, SP.

VISSERS, M.M. et al. Concentrations of butyric acid bactéria spores in silage and relationships with aerobic deterioration. Journal of Dairy Science, v.90, p.936-968, 2007. Disponível em: <http://download.journals.elsevierhealth.com/pdfs/journals/ 00220302/PIIS002203020771576X.pdf.>. Acesso em: 31 mar. 2011. doi:10.3168/jds.S0022-0302(07)71576-X. | 